\title{
Reflexóes sobre a realização de entrevistas com viúvas enlutadas em pesquisas qualitativas ${ }^{1}$
}

\author{
Marina Picazzio Perez Batista ${ }^{a}$, José Eduardo Rebelo ${ }^{b}$, Ricardo Tavares de Carvalhoc, \\ Maria Helena Morgani de Almeida ${ }^{a}$, Selma Lancman ${ }^{a}$
}

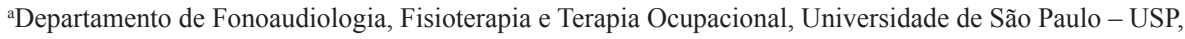
São Paulo, SP, Brasil.

'Departamento de Biologia, Universidade de Aveiro - UA, Aveiro, Portugal.

'Universidade de São Paulo - USP, São Paulo, SP, Brasil.

\begin{abstract}
Resumo: Introdução: Considerando que os enlutados são uma população mais vulnerável, é importante compreender os aspectos que se referem à realização de estudos qualitativos com esta população. Objetivo: Este artigo abordou uma reflexão sobre a realização de entrevistas com viúvas em processo de luto. Método: Realizou-se um estudo qualitativo, do tipo exploratório e descritivo, realizado com mulheres cujos cônjuges haviam falecido no período de dois a seis meses em decorrência de câncer. Todos os cônjuges tinham mais de 60 anos, e foram atendidos pela equipe de cuidados paliativos, no período de maio a outubro de 2015. As viúvas que aceitaram participar do estudo foram convidadas para uma entrevista individual. Para a sua condução foi utilizado um roteiro semiestruturado. O conteúdo das entrevistas foi gravado, transcrito e analisado pelo processo de codificação, gerando temas abrangentes. Resultados: As viúvas em luto citaram alguns benefícios por terem participado das entrevistas, tais como: primeira oportunidade para falar sobre sua perda; possibilidade para partilhar seus sofrimentos, trazendo certo alívio; maior confiança em suas capacidades; fortalecimento individual por falar do dia a dia; e também reflexão sobre o modo de viver seu cotidiano. Conclusão: A realização de entrevistas com enlutados favoreceu a escuta atenta e sem interrupção, permitindo-lhes partilhar suas experiências. De acordo com os benefícios apontados pelas viúvas no compartilhamento de suas vivências - no contexto de uma pesquisa qualitativa com entrevistas - foi possível inferir sobre a relevância da disponibilização de serviços de apoio ao luto, e também de favorer espaços de partilha aos enlutados em conformidade com suas demandas singulares.
\end{abstract}

Palavras-chave: Pesquisa Qualitativa, Entrevista, Luto, Viuvez.

\section{Reflections concerning the conduction of interviews with bereaved widows in qualitative survey}

\begin{abstract}
Introduction: Considering the vulnerability of the bereaved people, it is important to perceive aspects concerning qualitative studies conducted with this population. Objective: This article aimed to reflect on the implications of conducting individual interviews with widows in bereavement. Method: It is a qualitative exploratory and descriptive study. Its target population was women, whose spouses have died within the past 2-6 months due to cancer and were over the age of 60 and had been attended by the Palliative Care Service during the period May- October 2015. The widows that agree to participate in the study were invited to a private interview. For its conduction, a semi-structured guideline was used. The content of the interviews was recorded, transcribed and analyzed by the coding process, generating comprehensive themes. Results: The widows cited benefits for participating in the interviews: it was the first opportunity to talk about their loss; it allowed them to share her distress, favoring some
\end{abstract}

Autor para correspondência: Marina Picazzio Perez Batista, Curso de Terapia Ocupacional, Departamento de Fonoaudiologia, Fisioterapia e Terapia Ocupacional, Faculdade de Medicina da Universidade de São Paulo, Rua Cipotânea, n 51, Cidade Universitária, CEP 05360-000, São Paulo, SP, Brasil, e-mail: marinapperez@usp.br

Recebido em: Nov. 21, 2017; Aceito em: Jul. 23, 2018.

Este é um artigo publicado em acesso aberto (Open Access) sob a licença Creative Commons Attribution, que permite uso, distribuição e reprodução em qualquer meio, sem restrições desde que o trabalho original seja corretamente citado. 
relief; increased confidence in their abilities; contributed to their empowered by talking about his daily life; allowed reflection on the way of living their everyday life. Conclusion: Conducting interviews with bereaved encourages attentive and uninterrupted listening, allowing them to share their experience. Considering the benefits pointed out by the widows, as they shared their experiences in the context of a qualitative research with interviews, it is possible to infer the relevance of the provision of bereavement support services, favoring bereaved to have space for sharing, in accordance with their singular demands.

Keywords: Qualitative Research, Interview, Grief, Widowhood.

\section{Introdução}

O processo de luto desencadeia-se com uma experiência de privação, que pode ser sentida como uma perda pessoal e profunda de alguém significativo (REBELO, 2009; REBELO; LANCMAN; BATISTA, 2017). Perdas profundas são uma difícil realidade ao longo do ciclo de vida; especialmente pela morte de pais, cônjuges, filhos, irmãos e amigos (STROEBE et al., 2008; STROEBE et al., 2001).

O luto, ainda que seja uma experiência intrínseca à vida humana (REBELO; LANCMAN; BATISTA, 2017; SARTORI; BATTISTEL, 2017), acarreta intenso sofrimento para a maioria dos indivíduos (REBELO; LANCMAN; BATISTA, 2017). Inclusive, afigura-se como uma diversidade de vivências íntimas que pode causar considerável ruptura e desorganização na vida diária, principalmente nos primeiros meses após a morte de um ente querido (STROEBE; SCHUT; STROEBE, 2007; STROEBE et al., 2008; STROEBE et al., 2001). O tempo de luto é singular e está relacionado à necessidade do enlutado em restabelecer suas seguranças física e mental (REBELO, 2009).

Há estudos que visam revelar os significados únicos das reaçóes das pessoas à morte, assim como a outras perdas, e os mesmos são relevantes para o aprofundamento das pesquisas no campo do luto (NEIMEYER; HOGAN, 2001). Devido à idiossincrasia cultural dos comportamentos do luto, a abordagem qualitativa permite uma rica e aprofundada compreensão das experiências diárias do enlutado em seu contexto social. Os métodos qualitativos são bastante úteis nos estudos do luto, pois os dados originados auxiliam a contrabalancear as análises exclusivamente numéricas, que podem não exprimir com profundidade as especificidades vivenciais dos sujeitos (NEIMEYER; HOGAN, 2001).

A investigação qualitativa permite vislumbrar uma realidade com "densidade", sendo instigante e desafiadora (DUARTE, 2002). Sobretudo, é especialmente valiosa para revelar como as pessoas definem os seus eventos, e também para a compreensão mais minuciosa de um fenômeno em particular (NEIMEYER; HOGAN, 2001).
Dentre as principais abordagens qualitativas, destaca-se a realização de entrevistas. Este método de coleta de dados possibilita identificar e compreender os significados da vida cotidiana, revelando de um modo geral o invisível e inobservável (HASSELKUS, 2011). As entrevistas, por serem singularizadas, possibilitam ao pesquisador a obtenção de material "denso", único e com "profundidade" (WEISS, 1995).

Tendo em vista que os enlutados encontram-se frequentemente em uma condição de maior vulnerabilidade (COOK, 2001), é importante refletir sobre a condução das entrevistas qualitativas com esta populaçáa, particularmente para compreender suas experiências de luto. Entrevistas com esta finalidade foram realizadas no contexto de uma tese de doutorado (BATISTA, 2017). Apesar de não ter sido o principal objetivo da tese, a análise dos dados evidenciou o relato frequente e espontâneo das viúvas acerca de sua participação nas entrevistas. Pela relevância do tema, este artigo apresentou uma reflexão sobre a realização de estudos com viúvas enlutadas, os quais utilizam entrevistas qualitativas como procedimento de coleta de dados.

\section{Método}

Este artigo foi parte da tese de doutorado, um estudo de natureza qualitativa do tipo exploratório e descritivo. O objetivo da tese foi conhecer as atividades cotidianas de viúvas, cujos cônjuges faleceram em até seis meses (BATISTA, 2017).

Os critérios de inclusão da população-alvo foram: 1) ser residente no estado de São Paulo - Brasil; 2) ser viúva; 3) relacionar-se com o cônjuge que faleceu (casamento ou união estável); 4) ter perdido o cônjuge entre dois a seis meses antes da entrevista; 5) a morte do cônjuge ter decorrido de câncer; 6) o cônjuge que faleceu ter mais de 60 anos; e por fim, 7) ter sido atendido pela equipe do Núcleo de Cuidados Paliativos (NCP) do Hospital das Clínicas da Faculdade de Medicina da Universidade de São Paulo (HC-FMUSP), no período de maio a outubro de 2015. Para recrutamento da população alvo, o serviço de Cuidados Paliativos (CP) disponibilizou seu banco de dados com o registro dos atendimentos 
neste período, que contava com 462 pessoas. A partir dos critérios de inclusão, 36 potenciais participantes foram contatadas pelo telefone.

No contato telefônico, a pesquisadora esclareceu às viúvas acerca dos objetivos da pesquisa. Quando o telefone era atendido por outro familiar, explicitava-se sobre o estudo e solicitava-se o contato da esposa do cônjuge que havia falecido. Este contato telefônico foi realizado pela própria pesquisadora, pois se reconhece que a construção da relação com o entrevistado inicia-se no momento em que o potencial participante é esclarecido sobre o estudo (SEIDMAN, 2013).

As viúvas que aceitaram participar do estudo foram convidadas para uma entrevista individual. A pesquisadora disponibilizou-se a realizá-la no núcleo de $\mathrm{CP}$, em sala reservada para este fim, ou em outro local de conveniência das participantes.

Para a condução da entrevista foi adotado um roteiro semiestruturado. Deste modo, o instrumento de coleta de dados foi composto por uma de lista de questôes que direcionavam a entrevista, em conformidade com os objetivos da pesquisa (WEISS, 1995). O roteiro incluiu, portanto, perguntas semiestruturadas que buscavam identificar atividades cotidianas realizadas pelas participantes após a morte do esposo.

Conforme recomendado por Weiss (1995), a entrevista foi gravada para que náo houvesse perda de informaçóes, e posteriormente seu conteúdo foi transcrito. Nos resultados, foram apresentados trechos das entrevistas que ilustravam seu conteúdo, como preconizado pela literatura (WEISS, 1995; SEIDMAN, 2013). Para tanto, optou-se por apresentá-los da forma padronizada, ou seja, mantendo-se fiel às palavras das entrevistadas, porém editando os trechos para facilitar a compreensão do leitor (WEISS, 1995). Neste processo de edição buscou-se: a) compactar o discurso, reunindo partes do material que originalmente apareceram em tempos diferentes $\mathrm{da}$ transcrição, mas que se referiram à mesma questão; b) retirar trechos que dificultavam a leitura fluente (WEISS, 1995); c) retirar características próprias da linguagem oral que dificultavam o entendimento da narrativa, como as interjeiçóes e incorreçóes gramaticais (SEIDMAN, 2013); d) incluir entre colchetes palavras adicionadas pelo(a) pesquisador(a), visando facilitar a compreensão do(a) leitor(a) (WEISS, 1995); e) retirar ou substituir por outros similares, os conteúdos que permitiam a identificação da entrevistada (WEISS, 1995; SEIDMAN, 2013). A vantagem desta forma de apresentação do conteúdo foi permitir o discurso direto, favorecendo a atenção do(a) leitor(a) ao texto (WEISS, 1995). A menos que o objetivo da pesquisa seja realizar uma análise semântica do discurso, retirar vícios da linguagem oral no momento da escrita é uma obrigaçáo do(a) pesquisador(a) e também uma atitude respeitosa em relação ao(à) participante (SEIDMAN, 2013).

A análise dos dados foi iniciada somente após o término e transcrição de todas as entrevistas. Em conformidade com o que coloca Seidman (2013), este procedimento possibilitou ao pesquisador que o conteúdo trazido pelo participante não influenciasse a condução da entrevista subsequente no momento da coleta de dados. Optou-se por realizar a análise dos dados a partir do processo de codificação, frequentemente indicado para as entrevistas semiestruturadas (SALDAÑA, 2013).

A codificação, um dos métodos de análise de dados qualitativos (SALDAÑA, 2013), constitui-se como o processo de criação de códigos a partir de dados coletados (SEIDMAN, 2013; SALDAÑA, 2013). Entende-se este código, como uma palavra ou frase curta, que é desenvolvida pelo(a) pesquisador(a) para simbolizar, captar a essência, sintetizar e atribuir significado aos dados (SALDAÑA, 2013). Codificar, nesta perspetiva, é refletir acerca do material coletado (WEISS, 1995).

Entende-se que a codificação é um processo transitório, que ocorre entre a coleta de dados e sua análise mais aprofundada. Nesse sentido, torna-se uma etapa crucial da análise, pois a partir dela atribui-se uma lógica aos dados, permitindo explicá-los e lhes conceder significados. A partir da codificação, foi possível realizar o processo de categorização. Nesta etapa, os códigos foram agrupados por semelhança, criando-se padróes aos dados, e formando categorias, as quais traduziram um conteúdo mais abstrato quando comparadas ao código (SALDAÑA, 2013).

As categorias foram posteriormente analisadas, considerando suas possíveis correlaçóes para a criação de proposições mais ampliadas decorrentes deste processo de análise. Estas proposições, denominadas temas, traduziram uma concepção mais geral e abstrata dos dados (SALDAÑA, 2013).

No presente artigo foi apresentado o conteúdo relativo a um dos temas que emergiu desta análise dos dados. O tema foi relacionado às considerações das viúvas sobre suas participaçóes nas entrevistas semiestruturadas (BATISTA, 2017).

Como importante aspecto ético do estudo, vale ressaltar que a pesquisadora contatou a equipe de psicologia do núcleo de CP do HC-FMUSP, que se colocou à disposição para atender os familiares. Esta equipe permitiu que durante a pesquisa, os familiares identificados como pessoas que poderiam se beneficiar de apoio em seu processo de luto fossem encaminhados para atendimento no serviço. 
Em conformidade com as normas para a pesquisa prescritas pelo Conselho Nacional de Saúde (CNS), o projeto foi aprovado pela Comissão de Ética para Análise de Projetos de Pesquisa do HC-FMUSP, sob protocolo CAAE: 47511115.5.0000.0068, com a data de aprovação 19/08/2015. Todos os participantes assinaram o termo de consentimento livre e esclarecido.

\section{Resultados}

Com relação ao recrutamento da população alvo por contato telefônico, excluíram-se: 1) quatro esposas, pois o telefone estava incorreto, não havendo o contato; 2) duas esposas que não residiam em São Paulo; 3) e uma que havia falecido. Também neste quesito, houve 15 recusas pelos seguintes argumentos: i) seis filhos recusaram o estudo, e não permitiram que a pesquisadora o apresentasse às potenciais participantes, pois os mesmos acreditavam que suas mães não aguentariam o sofrimento de abordarem o tema em uma conversa específica para esta finalidade; ii) nove viúvas recusaram a participaçáo, algumas agradeceram o contato e a preocupação do hospital, mas náo se sentiram preparadas para falar sobre o tema naquele momento; iii) uma viúva referiu estar "muito brava" com a equipe do hospital, e precisava obter maiores informaçóes com os profissionais que atenderam seu marido, para compreender como ocorreu seu falecimento.

A partir dos critérios de inclusão e exclusão, assim como das recusas à pesquisa, o estudo foi realizado com 14 viúvas. Quanto à idade, 10 mulheres tinham 60 anos ou mais, e as outras tinham entre 55 e 59 anos. A média de idade das viúvas foi de 66 anos, e dos maridos de 74 anos. Apenas uma viúva tinha a mesma idade do marido, e as demais eram mais novas. Com base na escolaridade, a média foi de 6,6 anos de estudo. Em termos de ocupação laboral, observou-se: 1) duas esposas exerciam trabalho remunerado; 2) quatro estavam desempregadas; 3) três aposentadas, e 4) cinco nunca haviam trabalhado. Em termos de arranjo doméstico após o falecimento do cônjuge, metade vivia sozinha e a outra metade com familiares, especialmente filhos. Todas as esposas tinham pelo menos dois filhos, foram casadas somente uma vez, e tiveram casamentos de longa duração até a morte do cônjuge (média de 46 anos de casamento).

No que se refere especificamente às entrevistas, suas duraçôes médias foram de 1 hora e 36 minutos (variando entre 39 minutos a 3 horas e 50 minutos), perfazendo um total de 22 horas e 48 minutos de entrevistas. Somente quatro viúvas optaram por comparecer ao hospital para a participação na pesquisa. Verificou-se que no hospital as entrevistas tiveram maior duraçáo, pelo fato das participantes o terem considerado um lugar tranquilo para partilhar suas experiências. Outras 10 esposas preferiram ser entrevistadas em seus domicílios, por referirem que estavam debilitadas para se deslocarem pela cidade, e também pelo fato de se sentirem mais à vontade em sua casa porque não tiveram "coragem", "força" para irem novamente ao hospital em que o marido havia falecido.

Todas as participantes, cujas entrevistas ocorreram no hospital, afirmaram que haviam retornado ao local pela primeira vez desde a morte do marido. Referiram também que o caminho para a chegada ao serviço de $\mathrm{CP}$ trazia à memória o período de adoecimento do cônjuge. Neste sentido, foi necessário um cuidado da pesquisadora para lidar com estas situaçóes, sendo que a mesma procurou constantemente questionar se as viúvas preferiam remarcar a entrevista, ou então realizá-la em outro local, ou poderiam desistir de participar do estudo. Todas as viúvas optaram pela continuidade do processo, na medida em que sentiam que esta era uma forma positiva de enfrentarem o sofrimento decorrente de seu luto; conforme ilustrou a fala a seguir:

\section{P4: Eu não conseguia descer essa rua [...] hoje eu consegui $[. .$.$] eu estava com você [. .$.$] venci mais$ essa batalha.}

Em relação à entrevista, algumas participantes referiram estar surpresas ao receberem uma ligação do hospital no período de luto, após a morte do marido. Consideraram positiva a preocupação do serviço em telefonar e marcar conversas com os cônjuges enlutados; ainda que fosse dentro do contexto de uma tese de doutorado. Disseram que se sentiram acolhidas e cuidadas pelo serviço:

P1: Foi um presente ter alguém que teve a delicadeza, a preocupação de me ligar e querer saber de mim, independente se é para a sua tese.

Para uma participante, o contato com os familiares após o óbito foi relevante pois constitui-se um apoio para lidar com o processo de luto:

\section{P1: Eu acho fantástico esse trabalho, porque a família precisa desse respaldo.}

Algumas viúvas disseram que a entrevista foi uma oportunidade para falarem sobre seu cotidiano após a morte do cônjuge:

P6: Agradeço por essa oportunidade [...] poder falar sobre o men dia a dia depois que ele morreu. 
Outras disseram que nas entrevistas conseguiram expressar os sentimentos relacionados a seus processos de luto, o que lhes trazia alívio:

P6: Foi uma oportunidade de colocar para fora meus sentimentos.

P4: Eu achei alguém para conversar [...] estou colocando para fora [...] o que estava dentro de mim.

Uma viúva partilhou que poder falar sobre sua perda a fortalecia, pois lhe mostrava que poderia suportar o seu sofrimento, conforme descrito abaixo:

P1: Falar no assunto me fortalece, porque é sinal de que eu estou me superando [...] me dando a oportunidade de continuar a vida.

Para outra viúva, a entrevista permitiu repensar sobre a condução de seu cotidiano, e de como quebrar barreiras de isolamento que construiu desde o falecimento do cônjuge, em decorrência do intenso sofrimento que sentia no seu processo de luto. Segundo esta participante, falar sobre o tema a motivou realizar suas atividades e a prosseguir com a vida, mesmo na ausência de seu companheiro:

P4: Comecei a pensar em várias repostas que te dei [...] isso mudou muito a minha cabeça [...] não posso morrer junto com ele [...] é como se eu estivesse embrulhada, e rasguei o papel [...] é como se tivesse alguma barreira, alguma parede lá dentro. Agora alguma coisa se quebrou e eu joguei os tijolos fora.

Algumas participantes relataram que esta era a primeira vez que falavam abertamente sobre como estavam lidando com o seu processo de luto:

P8: A única pessoa que estou podendo falar é com você [...] tem horas que precisamos conversar e desabafar [...] você está entendendo o que eu estou sentindo.

Outra participante relatou que não partilhava com as filhas como se sentia, porque considerava que as mesmas náo demostravam disponibilidade para abordar este tema:

P7: Não temos a oportunidade de falar disso nem com as filhas [...] elas não têm tempo, nem disponibilidade de ficar escutando.

Com base na relação com os filhos, uma das viúvas partilhou com a equipe a preocupação de seu filho em saber que a mãe havia aceitado participar da entrevista. Ele considerava que conversar sobre o tema aumentaria a tristeza da mãe:
P8: Meu filho ficou preocupado, ele falou para mim: depois você vai ficar muito triste.

Porém, segundo esta mesma participante, o que ocorreu foi justamente o contrário do receio manifestado pelo filho. Ao final da entrevista, a viúva disse que sentia mais confiança em si mesma para lidar com o sofrimento do luto, e para reafirmar suas potencialidades para superar os desafios que estava enfrentando neste processo. Inclusive, a mesma relatou que a partir da entrevista pôde perceber que vivia um período de ajustes no cotidiano, relacionado intrinsicamente a uma vida que agora era marcada pela ausência de seu companheiro. Conforme trecho descrito abaixo:

P8: Não estou triste por conversar com você. Pelo contrário [...] despertou essa confiança [...] do modo como eu estou agindo [...] é uma fase de ajustes.

Em outra situação, identificou-se também a preocupação dos filhos em relação às mães, no fato de que nove entrevistas foram acompanhadas por eles. Ainda, para duas participantes que fizeram as entrevistas sozinhas, os filhos vinham à sala de entrevista sempre que escutavam seu choro. Observou-se que os filhos se tranquilizavam e se retiravam da sala quando os mesmos percebiam que, apesar do choro, a mãe se sentia confortável em partilhar seu sofrimento.

No que se refere à relação com os filhos, outra participante referiu que precisou buscar força interna para prosseguir com sua vida. Isto porque, esta participante tinha a sensação de que se ficasse em sua casa sofrendo ininterruptamente por sua perda, e se isolasse das pessoas, colocaria em risco o prazer que seus filhos sentiam ao estar em sua companhia. Segue abaixo trecho:

\section{P1: Choro na hora certa [...] se eu ficar chorando pelos cantos da casa, meus filhos não terão vontade de ficar perto de mim [...] vou me tornar uma viuva chata. Eles têm que chegar aqui e encontrar alegria, paz.}

Por último, vale destacar que quatro viúvas foram encaminhadas pela pesquisadora para atendimento pela psicologia, no ambulatório do Serviço de CP. Uma destas participantes havia sido a viúva que, no contato telefônico, referiu estar "muito brava" com a equipe do hospital, e "muito desestruturada" desde a morte do marido. Das 14 entrevistadas, apesar da possibilidade do atendimento pela psicologia ter sido oferecida a todas, somente três delas quiseram o encaminhamento, e o mesmo foi realizado. As demais referiram que apesar da grande tristeza 
que sentiam, percebiam que estavam bem com a gerência de seus processos de luto.

\section{Discussão}

Dentre os benefícios espontaneamente relatados pelas viúvas, em decorrência de sua participação em entrevistas que buscaram conhecer seu cotidiano no processo de luto pela morte do cônjuge em até seis meses, destacaram-se alguns pontos, tais como: 1) constituiu-se como primeira oportunidade para falar sobre sua perda; 2) permitiu partilhar seu sofrimento, trazendo certo alívio; 3) despertou maior confiança em suas capacidades; contribuiu para seu fortalecimento por falar do dia a dia; e por fim, 4) propiciou uma reflexão sobre o modo de viver seu cotidiano.

De um modo geral, a gestáo das expectativas sobre a vida, em particular no processo de luto recente, torna-se bastante difícil, pois a dor emocional é intensa e frequente (REBELO, 2009; VALE-TAYLOR, 2009). Relações duradouras com os cônjuges, tais como as encontradas no presente estudo, acarretam que o processo de luto seja comumente não linear (MCGRATH; HOLEWA; MCNAUGHT, 2010). Quando o luto é recente e a dor intensa, algumas pessoas precisam partilhar seu sofrimento, o que pode lhes trazer alívio (WEISS, 1995).

Neste sentido, acredita-se que estudos com entrevistas possam beneficiar seus participantes, porque este método de coleta de dados permite ao pesquisador: 1) apreender como a pessoa concebe o mundo; 2) favorecer o entendimento sobre a complexidade dos desafios que os(as) participantes enfrentam, e sobre suas percepçôes e experiências; 3) conhecer os eventos que lhes são significativos e o modo como afetam seus pensamentos e sentimentos, e 4) aceder aos significados que os(as) entrevistados(as) atribuem aos seus relacionamentos e a outros aspectos de suas vidas (WEISS, 1995).

Ainda neste tema, as pesquisas qualitativas, como as que envolvem entrevistas, permitem ao pesquisador observar as reaçôes dos participantes, e também de intervir ou até mesmo interromper a entrevista, em caso de necessidade (COOK, 2001). Neste contexto, compreende-se que a entrevista é uma parceria entre o respondente e o entrevistador (WEISS, 1995). Portanto, são requisitos fundamentais tanto o respeito ao participante quanto a escuta atenta e cuidadosa por parte do entrevistador, o qual deve expressar o desejo e demonstrar o interesse em conhecer a experiência partilhada pelo respondente (WEISS, 1995; SEIDMAN, 2013).
O pesquisador tem de ter sensibilidade para perceber se o(a) entrevistado(a) tem condiçóes para continuar a entrevista, e também de entender todas as pistas não verbais que ele(ela) fornece (WEISS, 1995; SEIDMAN, 2013). De igual modo, deve-se estar atento para conter seus próprios gestos de expressão corporal, que possam se traduzir em mensagens, sejam de aprovação ou rejeição, do conteúdo partilhado pelo(a) entrevistado(a) (DUARTE, 2002). As entrevistas de qualidade partem da premissa de que o(a) entrevistador(a) deve falar menos que o(a) entrevistado(a), ou seja, compete-lhe o exercício da escuta ativa (WEISS, 1995; SEIDMAN, 2013).

Entretanto, o(a) entrevistador(a) deve assegurar ao participante que, em caso de necessidade, se encontra disponível para ser contatado. Sabe-se que esta exigência ética da investigação torna-se ainda mais relevante em estudos com enlutados, por serem uma população emocionalmente muito vulnerável (COOK, 2001). Em pesquisas com entrevistas, cujo foco se refere à perda de pessoas amadas, deve-se esclarecer explicitamente que o enlutado pode interromper a entrevista a qualquer momento (HOPPES; SEGAL, 2010). Todos estes procedimentos foram adotados nas entrevistas deste artigo, e acredita-se que os mesmos possam ter favorecido a partilha.

Acredita-se também que os resultados favoráveis à realização das entrevistas deste estudo tenham sido relacionados ao tipo de entrevista adotado: a semiestruturada. Neste caso, o(a) entrevistador(a) tem de direcionar o(a) respondente para os tópicos relacionados ao estudo, permitindo-lhe abertura para que aborde outras questôes, caso sinta necessidade (WEISS, 1995). É possível apresentar questôes que auxiliem o(a) entrevistado(a) a elucidar tópicos que requeiram maior esclarecimento (WEISS, 1995; SEIDMAN, 2013), dedicando atenção à não interrupçáo do(a) entrevistado(a) e à não formulação de perguntas inapropriadas, que possam levá-lo a assumir uma postura defensiva na entrevista ou a perder a vontade de partilhar (SEIDMAN, 2013).

A atenção ao decurso temporal da entrevista também deve ser cuidada, tendo em consideração o que foi partilhado sobre o tópico em análise, e quais os aspectos que ainda faltam abordar (WEISS, 1995; SEIDMAN, 2013). Verifica-se que, temas como experiências pessoais e relatos de sentimentos favorecem a livre expressáo, incorrendo no risco da entrevista se desviar do tópico de pesquisa ou ainda, de se estabelecer uma troca de experiências entre respondente e pesquisador(a) - fato que afetaria negativamente a qualidade do estudo (DUARTE, 2002). 
Acredita-se que a possibilidade concedida aos enlutados de poderem escolher o local onde a entrevista se realizaria também contribuiu para gerar os benefícios para as viúvas, mencionados no presente estudo. Duarte (2002) considerou que os participantes optam, em regra geral, por receberem a pesquisadora em sua casa, devido ao ambiente privado, confortável e propício à revelação segura dos sentimentos. Deste modo, possibilita que as entrevistas sejam mais longas e com maior profundidade. Este estudo confirmou a primeira asserção sobre a dinâmica de escolha domiciliar para o local da sessão com as viúvas enlutadas, verificando que a maioria preferiu falar sobre sua perda em casa. Em contrapartida, quanto à dimensão temporal, identificou-se que a entrevista mais longa ocorreu com uma das participantes que se deslocou ao hospital onde o marido havia falecido. Esta viúva encontrou na sala do serviço de CP um local tranquilo para a expressão dos sentimentos e experiências cotidianas em seu processo de luto; tendo em vista que este local suscitou recordaçóes do adoecimento e morte do marido que favoreceram abordar o tema.

Considerou-se que, outro fator que favoreceu a coleta de dados deste estudo e a perceçáo positiva das mulheres enlutadas sobre a partilha, foi a colaboração à pesquisa efetuada pela equipe do serviço de CP. Dentre muitos aspectos, destacaram-se: 1) o interesse e grande abertura do chefe do serviço para o desenvolvimento do estudo; 2) a disponibilizaçáo pela equipe de recursos, como uma sala reservada para entrevista e uma linha telefônica para o contato com as enlutadas; e, 3) o cuidado da equipe de psicologia em assegurar o atendimento às pessoas que foram identificadas durante a pesquisa com necessidade de auxílio no enfrentamento do luto.

Assim, acredita-se que os cuidados adotados na condução das entrevistas neste estudo favoreceram os potenciais benefícios citados pelas participantes. Reconhece-se que, em geral, os elementos propiciados na entrevista não são viáveis em conversas informais com a rede de suporte; e muitas vezes, a entrevista converte-se em uma primeira possibilidade que o enlutado possui de abordar, de forma sistemática, as vivências por ele experienciadas (WEISS, 1995; COOK, 2001). Tal fato, pôde ser explicitado por uma viúva que referiu ser a primeira vez que podê contar como se sentia neste processo, pois suas filhas não tinham disponibilidade ou condiçóes emocionais de abordarem o tema com a máe.

De um modo geral, o relacionamento de viúvas em luto com os filhos é complexo e, por vezes, conflituoso, devido ao rearranjo necessário dos papéis familiares decorrentes das perdas conjugal e parental, respectivamente. Neste estudo, observou-se uma contradição entre o sentimento de um filho e de uma das viúvas sobre a participação na entrevista. Esta última exprimiu benefícios da participação na entrevista para seu processo de luto, ao passo que o filho se preocupou com o aumento do sofrimento que a mãe pudesse vir a experienciar. Este receio dos filhos exprimiu-se também pela recusa do contato telefônico da pesquisadora com suas mães viúvas, ou pela vigilância permanente das mães no decurso da entrevista, particularmente nos momentos de expressão de tristeza. As reaçóes ao contato telefônico e ao momento da coleta de dados, assim como gestos e posturas e o grau de disponibilidade do entrevistado, foram e são elementos relevantes para a compreensão mais aprofundada do universo estudado (DUARTE, 2002).

Talvez, o comportamento de proteção dos filhos possivelmente esteja relacionado com a percepção da grande vulnerabilidade das mães no processo de luto (MOSS; MOSS, 2014), sobretudo com a crença de que explicitar seu sofrimento diminuiria sua capacidade de enfrentamento. Conforme Sartori e Battistel (2017):

A morte é um tema que causa muito desconforto para a maioria das pessoas (...) a sociedade, de modo geral, não interpreta como algo que deveria fazer parte do ciclo vital. É uma visão social constituída que instiga as pessoas a rejeitá-la como parte desse ciclo. Nega-se a morte dizendo que não se sabe conviver com a ideia ou que não se quer refletir sobre o assunto (SARTORI; BATTISTEL, 2017, p. 506).

Também é possível inferir que o comportamento de proteção dos filhos se relacione com seu próprio luto pela morte do pai. Após a perda de um progenitor, o filho pode temer experienciar a perda da outra figura parental, e desta maneira se protege, tentando diminuir o sofrimento da mãe, com o receio de que o aumento da dor possa provocar a morte dela. De acordo com Rebelo, Lancman e Batista (2017), os membros próximos da rede de suporte, com frequência, não se encontram preparados para auxiliar o enlutado, porque eles mesmos vivenciavam um luto em relação à pessoa morta, ou porque têm dificuldades em lidar com experiências de perda.

Ademais, o comportamento dos filhos poderia estar relacionado com o fato de considerarem que uma importante estratégia para as viúvas atenuarem o sofrimento do luto seria seguirem em frente, retomando sua rotina o mais rapidamente possível. $\mathrm{Na}$ tentativa de ajudar o enlutado a retomar o 
controle sobre sua vulnerabilidade e instabilidade emocional, as pessoas buscam minimizar a perda (HARRIS, 2009). Os enlutados podem se sentir pressionados a desviarem-se do passado, ao invés de ressignificá-lo e incorporá-lo ao presente. Do mesmo modo, os mesmos também podem sentir-se forçados a seguir em direção a um futuro que lhes é incerto (WAMBACH, 1985). Este contexto social está relacionado com os valores que regem a sociedade ocidental, que valoriza a manutenção do controle emocional e da funcionalidade, e que náo tolera a diminuição da produtividade - frequentemente observada nas pessoas em luto (HARRIS, 2009; REBELO; LANCMAN; BATISTA, 2017). Logo, o enlutado tem de negligenciar sua experiência de sofrimento, prejudicando a assimilação da multiplicidade de detalhes vivenciais que envolvem a perda (REBELO; LANCMAN; BATISTA, 2017).

As expectativas ocidentais, de uniformidade e conformidade com as regras de conduta consideradas aceitáveis, exercem muita influência sobre os enlutados, prolongando seu sofrimento. Entende-se, portanto, que o sofrimento do enlutado é geralmente influenciado pela forma em que suas respostas são percebidas pelas pessoas com as quais convive, incluindo familiares, amigos, colegas de trabalho e profissionais de saúde (HARRIS, 2009). Portanto, a preparação dos profissionais de saúde para compreender e acolher pessoas em situaçóes de perda, morte e luto, deve ser priorizada desde a graduação (SARTORI; BATTISTEL, 2017).

A dissimulação dos sentimentos de tristeza em presença de outras pessoas, pode ser uma estratégia utilizada pelo enlutado para evitar o isolamento. Assim como observado com uma das participantes deste estudo, as viúvas, não raramente, esforçam-se para exibir alegria na presença dos filhos, pelo receio de que estes venham a deixar de sentir prazer em seu convívio. Outros estudos também apontaram que o controle da expressão emocional por viúvas diante dos filhos decorria do receio de que eles as julgassem como vulneráveis e carentes, ou por elas mesmas acreditarem que sua instabilidade emocional os pudesse incomodar. Paradoxalmente, as viúvas enlutadas percebiam que o comportamento de esconder seus sentimentos diminuía a capacidade dos filhos de reconhecerem as perturbaçóes emocionais que experienciavam em consequência da perda (HARRIS, 2009; MOSS; MOSS, 2014). Em outro estudo, verificou-se que muitos enlutados preferiam não ficar "remoendo sua perda" por não acharem adequado demonstrar excessivamente seus lutos, e também por considerarem esta atitude como um comportamento mórbido e depressivo
(BLACK; SANTANELLO, 2012). As emoçóes e os comportamentos provocados pelo luto são frequentemente considerados como inapropriados na cultura ocidental, que exerce pressóes que impelem o enlutado a inibir a manifestaçáo pública de seus sentimentos (BLACK; SANTANELLO, 2012; REBELO; LANCMAN; BATISTA, 2017).

Sabe-se que a morte e o luto evidenciam a vulnerabilidade do ser humano e são julgados pela sociedade ocidental como sinal de fraqueza. Todavia, internalizando as forças opressivas exercidas pelas regras sociais (HARRIS, 2009; REBELO; LANCMAN; BATISTA, 2017), os enlutados podem tentar "mascarar" os sentimentos de seu luto, ou encontrar diferentes formas de manifestá-lo quando estão sozinhos (MOSS; MOSS, 2014; HARRIS, 2009). As oportunidades que os enlutados possuem para partilharem suas perdas são escassas, pois existe uma expectativa comum de que as pessoas lidem com seu luto de forma privada e rápida, dando continuidade à sua vida. Tal atitude pode transmitir subliminarmente a mensagem de que o sofrimento do enlutado não é legítimo ou de que a intensidade de sua perda não é completamente reconhecida.

Neste contexto, os estudos sobre o luto de viúvas foram e são relevantes, tendo em consideração as contradiçóes experienciadas por elas na vida cotidiana. Este artigo confirmou que a participação das viúvas nas entrevistas, espaço em que puderam partilhar seus sentimentos do luto, fez com que as mesmas sentissem alívio em seus sofrimentos. A realização de entrevistas com enlutados - que ofereça escuta atenta e sem interrupçáo e permita partilhar a experiência (WEISS, 1995), pensamentos e sentimentos relacionados à perda (COOK, 2001; MOSS; MOSS, 2014) - pode, assim, trazer benefícios aos participantes. Este processo potencialmente contribui para a elaboração e atribuição de novos significados à experiência, podendo acarretar mudanças na forma de condução da vida (WEISS, 1995). Entendeu-se que este processo exitoso no que tange à partilha adveio também do fato de que foram entrevistadas as viúvas que aceitaram participar do estudo, tal como preconizado pelas regras éticas de pesquisa com seres humanos, o que demonstra a relevância do respeito ao momento e disponibilidade interna da pessoa para a partilha de seu processo de luto.

Reconhece-se que o apoio ao enlutado náo se constitui como objetivo principal de pesquisas, as quais utilizam entrevistas como procedimento de coleta de dados. Porém, vislumbra-se que estudos com seres humanos tragam benefícios aos participantes - $\mathrm{de}$ fato, um aspecto ético bastante valorizado no âmbito 
nacional com a análise e aprovação de projetos de pesquisa pelos Comitês de Ética (BRASIL, 2002).

Acrescenta-se que os benefícios referidos pelas viúvas apontaram para a necessidade de disponibilização de mais espaços para apoio às pessoas em luto. Nesta perspectiva, identifica-se o terapeuta ocupacional como profissional privilegiado para apoiar esta população. Conforme Sartori e Battistel (2017), os autores descreveram que no cotidiano se convive com o impacto causado pela morte de uma pessoa significativa.

O apoio ao luto das viúvas, cujos cônjuges faleceram em ambiente hospitalar, mesmo que seja no contexto de uma tese de doutorado, foi considerado como relevante pelas participantes desta pesquisa. Verificou-se uma surpresa positiva ao receberem contato telefônico do hospital após a morte do marido, pois se sentiram cuidadas pelo núcleo de CP do HC-FMUSP. Os resultados apontaram a relevância do cuidado das equipes hospitalares com os familiares enlutados após a morte de um paciente.

O "follow-up" realizado pelos serviços hospitalares aos viúvos após o óbito do cônjuge, seja por meio do contato telefônico, grupos de partilha do luto, ou de intervençóes terapêuticas, auxiliou na gestão de processos de luto. Uma minoria de viúvos não considerou necessário este "follow-up", pois seus recursos de suporte informais e/ou seus recursos pessoais para lidarem sozinhos com o seu sofrimento eram suficientes para enfrentarem seus processos de luto (MCGRATH; HOLEWA; MCNAUGHT, 2010).

Neste sentido, a maioria dos enlutados não recorre às intervençôes profissionais de apoio ao luto, uma vez que sua rede social concede o suporte necessário para este momento (STROEBE; SCHUT; STROEBE, 2007). Porém, considerou-se que a sistematização do contato de equipes hospitalares com os familiares de um paciente falecido, favorece a identificação daqueles que necessitam de intervenção profissional no auxílio a seus processos de luto. Portanto, verificou-se neste trabalho que embora algumas viúvas se recusaram a participar do estudo, por não se sentirem preparadas para conversarem sobre o tema, as mesmas sentiram-se acolhidas pelo serviço hospitalar ao receberem um telefonema do hospital.

Apesar do luto ser um evento normal da vida de todo ser humano, o mesmo deve ser considerado como uma questão de saúde pública (BERGMAN; HALEY; SMALL, 2010; REBELO; LANCMAN; BATISTA, 2017), porque em alguns casos, pode haver uma predisposiçâo do enlutado a uma maior fragilidade para doenças (BERGMAN; HALEY; SMALL, 2010).

Em princípio, a privação de uma pessoa amada acarreta algumas manifestaçóes distintas, que podem em determinadas situaçóes requererem apoio, tais como: 1) afetivas: desânimo, desespero, tristeza, desamparo, desesperança, ansiedade, culpa, raiva, hostilidade, anedonia, solidão; 2) comportamentais: agitação, fadiga, choro, isolamento social, modificaçōes na administração de medicamentos; 3) cognitivas: pensamentos de preocupação pela pessoa falecida, baixa autoestima, autocensura, sentimento de irrealidade, problemas de memória e concentração; e, 4) fisiológicas: perda de energia, queixas somáticas, distúrbios do sono, perda de apetite, queixas físicas similares às quais $\mathrm{o}$ (a) falecido (a) padecia, susceptibilidade à doença, como câncer e ataques cardíacos (STROEBE et al., 2001; STROEBE; SCHUT; STROEBE, 2007; STROEBE et al., 2008; NAEF et al., 2013). Logo, o processo de luto é complexo, e apresenta-se como múltiplas manifestaçôes que variam conforme o sujeito, a cultura, o tempo do luto e a rede de suporte, dentre outros aspectos (STROEBE et al., 2008; REBELO, 2009).

Os custos financeiros decorrentes do luto podem ser elevados, considerando que os enlutados apresentam maiores riscos de depressão, ansiedade, queixas somáticas, assim como propensão às infecçóes e doenças. Em consequência disto, as consultas dos enlutados aos profissionais de saúde são mais frequentes, bem como o uso de medicação, além da hospitalização e evidência de outras incapacidades (STROEBE, 2009; STROEBE; SCHUT; STROEBE, 2007; STROEBE et al., 2001). Em casos mais raros, os mesmos desenvolvem transtornos mentais (STROEBE; SCHUT; STROEBE, 2007), demonstrando também, maior risco de mortalidade associado a diversas causas (STROEBE et al., 2001), particularmente nos primeiros meses após a perda (STROEBE, 2009; STROEBE; SCHUT; STROEBE, 2007; STROEBE et al., 2001). Dentre estas causas, inclui-se o suicídio (STROEBE et al., 2001) e a síndrome do coração partido - manifestada por um infarto agudo do miocárdio (STROEBE, 2009). Mais raramente, em um reduzido número de pessoas, as reaçóes à perda podem levar à morte do enlutado (STROEBE, 2009).

Assim, o luto é uma questáo relevante para o cuidado preventivo e para a prática clínica (STROEBE; SCHUT; STROEBE, 2007). Conforme verificou-se neste estudo, houve necessidade de encaminhamento de algumas participantes ao ambulatório de psicologia do serviço de CP. Nesta perspectiva, a 
disponibização de estruturas de acompanhamento dos familiares enlutados, apoiando-os em seus processos de luto quando necessário, é de elevada relevância tanto nas gestóes individual quanto social do luto (WORLD..., 2007; WORLD...; WORLDWIDE..., 2014). Vale ainda destacar que se acredita ser importante durante a hospitalizaçáo que a equipe se disponibilize a apoiar os familiares em seus processos de luto, para que possam recorrer a este auxílio caso sintam necessidade. No entanto, se este cuidado após o falecimento do cônjuge for interrompido, é provável que as viúvas sintam nesta suspensão outra perda, que se adicionará ao complexo processo de luto que vivenciam.

Mas ressalta-se que a rede de serviços a enlutados, não deve se restringir ao cuidado no âmbito hospitalar, e sim abranger todos os níveis de atenção, com o fortalecimento da atenção primária em saúde. Neste estudo, a maioria das viúvas preferiu ser entrevistada em suas casas, em razão da dificuldade de deslocamento, ou por não se sentir preparada para voltar ao hospital em que ocorreu o falecimento do marido.

O fortalecimento da atenção primária no apoio ao luto é desejável na organização do sistema de cuidados. Evidenciou-se que existe uma alta prevalência de processos de luto entre idosos, e também a tendência da atenção primária em atuar como o principal nível de prestação de cuidado a esta população (GHESQUIERE et al., 2014). Também se destacou a valorização pelos cônjuges enlutados da consulta do médico de família como espaço de compartilhamento dos sentimentos do luto (BERGMAN; HALEY; SMALL, 2010).

Identificou-se que os sofrimentos manifestados pelos usuários da atenção primária em saúde são muitas vezes sintomas de processos de luto, sendo incorretamente ou desnecessariamente tratados com a prescrição de psicofármacos (SANTOS; GANDOLF, 2015). Neste contexto, o acompanhamento das pessoas enlutadas neste nível de atenção deve objetivar dentre outros aspectos, a detecçáo e prevenção das condiçóes que podem acarretar em luto psicopatológico (CHARLTON et al., 2001; GARCÍA-VINIEGRAS; GRAU ABALO; PEDREIRA, 2014); além da realização de encaminhamentos para o apoio especializado em caso de necessidade (GARCÍA-VINIEGRAS; GRAU ABALO; PEDREIRA, 2014).

Portanto, a disponibilização de uma rede abrangente de serviços comunitários, em uma perspectiva intersetorial e territorial de proximidade aos enlutados, constitui-se como resposta social indispensável para o cuidado implicado às pessoas em luto (REBELO; LANCMAN; BATISTA, 2017;
BERGMAN; HALEY; SMALL, 2010; WORLD..., 2007).

\section{Considerações Finais}

Ainda que os métodos qualitativos sejam incipientes na investigação do luto, os mesmos têm permitido evidenciar a complexidade e idiossincrasia das problemáticas atinentes a este processo. A abordagem qualitativa é, assim, propícia ao enriquecimento, aprofundamento e inovação nas áreas de estudos do luto (NEIMEYER; HOGAN, 2001).

O método de entrevista permite ao sujeito partilhar sua história, por meio de um relato em que seleciona detalhes de suas experiências, e os ordena em uma sequência que favorece sua melhor compreensão. Ao simbolizar sua experiência pela linguagem, a pessoa têm a possibilidade de refletir sobre ela e novos significados podem ser a ela atribuídos (SEIDMAN, 2013).

As viúvas entrevistadas neste estudo expressaram benefícios resultantes da participação nas entrevistas, nas quais puderam partilhar suas vivências do luto. Pelos resultados, é possível inferir que estes benefícios sejam potencializados em espaços de partilha com profissionais capacitados para manejo das questóes que envolvem processos de luto. Acredita-se que o terapeuta ocupacional, por compreender e intervir no impacto das perdas no cotidiano (SARTORI; BATTISTEL, 2017), seja profissional relevante nas equipes que apoiem as pessoas em luto.

Ainda, os resultados permitiram inferir a relevância da disponibilização de serviços de apoio ao luto, a fim de que as pessoas que vivenciam sofrimentos decorrentes de perdas possam acessá-los em conformidade com suas necessidades singulares (REBELO; LANCMAN; BATISTA, 2017). Nesses serviços, é fundamental a articulação entre os distintos níveis de atenção.

\section{Referências}

BATISTA, M. P. P. Significados atribuidos às atividades cotidianas de mulheres após a morte em até seis meses do cônjuge idoso. 2017. 174 f. Tese (Doutorado em Ciências) - Universidade de São Paulo, São Paulo, 2017.

BERGMAN, E. J.; HALEY, W. E.; SMALL, B. J. The role of grief, anxiety, and depressive symptoms in the use of bereavement services. Death Studies, Washington, v. 34, n. 5, p. 441-458, 2010

BLACK, H. K.; SANTANELLO, H. R. The salience of family worldview in mourning an elderly husband and father. Gerontologist, Cary, v. 52, n. 4, p. 472-483, 2012. 
BRASIL. Ministério da Saúde. Conselho Nacional de Saúde. Comissão Nacional de Ética em Pesquisa. Manual operacional para comitês de ética em pesquisa. Brasília: Ministério da Saúde, 2002.

CHARLTON, R. et al. Spousal bereavement-implications for health. Fam Pract, Oxford, v. 18, n. 6, p. 614-618, 2001.

COOK, A. S. The dynamics of ethical decision making in bereavement research. In:STROEBE, M. A. et al. (Ed.). Handbook of Bereavement Research: Consequences, Coping, and Care. Washington: American Psychological Association, 2001. p. 119-142.

DUARTE, R. Pesquisa qualitativa: reflexóes sobre o trabalho de campo. Cadernos de Pesquisa, São Paulo, n. 115, p. 139-154, 2002.

GARCÍA-VINIEGRAS, C. R. V.; GRAU ABALO, J. A.; PEDREIRA, O. I. Duelo y proceso salud-enfermedad en la Atención Primaria de Salud como escenario para su atención. Revista Cubana de Medicina General Integral, Ciudad de La Habana, v. 30, n. 1, p. 121-131, 2014.

GHESQUIERE, A. R. et al. Primary care providers' bereavement care practices: recommendations for research directions. International Journal of Geriatric Psychiatry, Chichester, v. 29, n. 12, p. 1221-1229, 2014. http:// dx.doi.org/10.1002/gps.4157.

HARRIS, D. Oppression of the bereaved: a critical analysis of grief in Western society. Omega, Los Angeles, v. 60, n. 3, p. 241-253, 2009.

HASSELKUS, B. R. Meaning: an essential for life. In: HASSELKUS, B. R. (Ed.). The meaning of everyday occupation. Grove Road: SLACK Incorporated, 2011. s.p.

HOPPES, S.; SEGAL, R. Reconstructing meaning through occupation after the death of a family member: accommodation, assimilation, and continuing bonds. Am J Occup Ther, Boston, v. 64, n. 1, p. 133-141, 2010. http://dx.doi.org/10.5014/ajot.64.1.133.

MCGRATH, P.; HOLEWA, H.; MCNAUGHT, M. Surviving spousal bereavement insights for GPs. Aust Fam Physician, Sydney, v. 39, n. 10, p. 780-783, 2010.

MOSS, M. S.; MOSS, S. Z. Widowhood in old age: viewed in a family context. J Aging Stud, Greenwich, v. 29, p. 98-106, 2014. http://dx.doi.org/10.1016/j. jaging.2014.02.001.

NAEF, R. et al. Characteristics of the bereavement experience of older persons after spousal loss: an integrative review. International Journal of Nursing Studies, Oxford, v. 50, n. 8, p. 1108-1121, 2013. http://dx.doi.org/10.1016/j. ijnurstu.2012.11.026.

NEIMEYER, R. A.; HOGAN, N. S. Quantitative or qualitative? Measurement issues in the study of grief. In: STROEBE, M. S. et al. (Ed.). Handbook of bereavement research: consequences, coping, and care. Washington: American Psychological Association, 2001. p. 89-118. http://dx.doi.org/10.1037/10436-004.

REBELO, J. E. Amor, luto e solidão. Lisboa: Casa das letras, 2009.
REBELO, J. E.; LANCMAN, S.; BATISTA, M. P. P. Perspectivas sobre as estruturas náo governamentais e a ação comunitária no apoio ao luto em Portugal e o "Modelo Vivencial do Luto Sadio". Revsita de Terapia Ocupacional da Universidade de São Paulo, São Paulo, v. 28 , n. 1, p. 1-8, 2017.

SALDAÑA, J. The coding manual for qualitative researchers. London: SAGE Publications Ltd, 2013.

SANTOS, J. E.; GANDOLF, L. Sentidos do sofrimento no contexto da atenção primária. Medicina, Ribeirão Preto, v. 48, n. 4, p. 321-327, 2015.

SARTORI, A. V.; BATTISTEL, A. L. T. A abordagem da morte na formação de profissionais e acadêmicos da enfermagem, medicina e terapia ocupacional. Cadernos Brasileiros de Terapia Ocupacional, São Carlos, v. 25, n. 3, p. 497-508, 2017.

SEIDMAN, I. Interviewing as qualitative research: a guide for researchers in education and the social sciences. New York: Teachers College Press, 2013.

STROEBE, M. S. Beyond the broken heart: Mental and physical health consequences of losing a loved one. Psychologie \& Gezondheid, Groningen, v. 37, n. 5, p. 241-251, 2009.

STROEBE, M. S. et al. Bereavement research: contemporary perspectives. In: STROEBE, M. S. et al. (Ed.). Handbook of bereavement research and practice: advances in theory and intervention. Washington: American Psychological Association, 2008. p. 3-25. http://dx.doi.org/10.1037/14498-001.

STROEBE, M. S. et al. Introduction: concepts and issues in contemporary research on bereavement. In: STROEBE, M. S. et al. (Ed.). Handbook of bereavement research: consequences, coping, and care. Washington: American Psychological Association, 2001. p. 3-22. http://dx.doi. org/10.1037/10436-031.

STROEBE, M.; SCHUT, H.; STROEBE, W. Health outcomes of bereavement. Lancet, London, v. 370, n. 9603, p. 1960-1973, 2007.

VALE-TAYLOR, P. "We will remember them": a mixedmethod study to explore which post-funeral remembrance activities are most significant and important to bereaved people living with loss, and why those particular activities are chosen. Palliative Medicine, London, v. 23, n. 6, p. 537-544, 2009.

WAMBACH, J. A. The grief process as a social construct. Omega-Journal of Death and Dying, New York, v. 16, n. 3, p. 201-211, 1985. http://dx.doi.org/10.2190/XBB0LHXE-FDLH-8Q9M.

WEISS, R. S. Learning from strangers: the art and method of qualitative interview studies. New York: The Free Pass, 1995.

WORLD HEALTH ORGANIZATION - WHO. Cancer control: knowledge into action - WHO guide for effective programmes. Geneva: World Health Organization, 2007.

WORLD HEALTH ORGANIZATION - WHO; WORLDWIDE PALLIATIVE CARE ALLIANCE WPCA. Global atlas of palliative care at the end of life. London: Worldwide Palliative Care Alliance, 2014. 


\section{Contribuição dos Autores}

Marina Picazzio Perez Batista é autora da tese que originou este artigo, participou de todas as etapas da pesquisa, inclusive com a escrita da tese e do presente artigo. José Eduardo Rebelo foi o Professor que orientou a autora principal durante seu doutorado sanduíche em Portugal, o qual participou da análise dos dados da tese e da redaçáo deste texto. Ricardo Tavares de Carvalho participou da elaboraçáo do artigo, especialmente na discussão dos dados e no processo de revisão, sendo que ao longo do desenvolvimento da tese contribuiu no desenho metodológico, favorecendo a condução das entrevistas. Maria Helena Morgani de Almeida contribuiu na discussão dos dados da tese, em especial nos conteúdos referentes à sua área de atuação, sobretudo participou da elaboração e revisão do texto. Selma Lancman foi orientadora da tese de doutorado que originou o artigo, orientou em todas as etapas da pesquisa, redigiu e revisou todo o texto. Todos os autores aprovaram a versão final do texto.

\section{Notas}

${ }^{1}$ Este artigo é fruto da tese de doutorado intitulada "Significados atribuidos às atividades cotidianas de mulheres após a morte em até seis meses do cônjuge idoso", apresentada à Faculdade de Medicina da Universidade de São Paulo (FMUSP) Brasil- para obtenção do título de Doutor em Ciências pelo Programa de Ciências da Reabilitação. Este artigo foi escrito em cooperação internacional entre a Faculdade de Medicina da Universidade de São Paulo- Brasil, e o Departamento de Biologia da Universidade de Aveiro-Portugal, dado que parte da tese de doutorado foi realizada em estágio de pesquisa em Portugal. De acordo com as normas para pesquisa propostas pelo Conselho Nacional de Saúde do Brasil, o projeto foi aprovado pelo Comitê de Ética em Pesquisa do Hospital das Clínicas da Faculdade de Medicina da Universidade de São Paulo (CEP- FMUSP), sob protocolo CAAE: 47511115.5.0000.0068, data de aprovação 19/08/2015. 